\title{
Analysis of emerging technology adoption for the digital content market
}

\author{
Bih-Huang Jin $\cdot$ Yung-Ming Li
}

Published online: 15 January 2012

(C) Springer Science+Business Media, LLC 2012

\begin{abstract}
The digital content market is undergoing an evolution in networking and digitalization technologies, offering diverse information and services. Due to the characteristics of these emerging technologies, the digital content market is growing rapidly and traditional content providers face service transformation decisions. While a majority of the previous technology adoption studies have focused on the viewpoints of users and customers, cost reduction, or electronic channel related technologies, in this research we analyze the emerging technology adoption decisions of competing firms for providing new content services from a strategic perspective. Utilizing game theoretical models, we examine the effects of market environments (technology cost, channel cannibalization, brand power, brand extension, information asymmetry and market uncertainty) on firms' adoption decisions. This research contributes a number of unique and interesting implications for the issues of emerging technology adoption for new content service provision.
\end{abstract}

Keywords Economic analysis - Strategic technology adoption - Digital content industry - Game theoretical model $\cdot$ Market uncertainty $\cdot$ Asymmetry information

B.-H. Jin

Department of Business Administration, Tunghai University,

Taichung 400, Taiwan

e-mail: bihuang@thu.edu.tw

Y.-M. Li (ه)

Institute of Information Management, National Chiao Tung

University, Hsinchu 300, Taiwan

e-mail: yml@mail.nctu.edu.tw

\section{Introduction}

Recent developments in enabling technologies have given a tremendous push toward the development of digital content services such as digital books, publishing, print, music, and video. Various types of digital content have come together to form new products and services. Compared with other traditional content markets, the digital content market is undergoing rapid changes. The average global annual growth rate of the digital content market has been exponential [31]. Based on the forecast analysis by PricewaterhouseCoopers of the global entertainment and media market, the market is expected to rise from US $\$ 1.3$ trillion in 2009 to $\$ 1.7$ trillion by 2014 , growing at a compound annual growth rate (CAGR) of 5.0\% [20].

Emerging digitalization technology alleviates the need to produce, store, and distribute physical goods [40]. Digital goods can be delivered via the Internet which eliminates physical products altogether. These technological developments have opened up new markets, new services, new products and changed the ecosystem in the content market value chain [5, 34]. Consequently, with the exponential growth of Internet availability to consumers, traditional content providers are afraid that if they do not offer digital goods and services online, they will lose their customers to the competitors and enable successful entry of new firms [22]. The traditional content providers such as book publisher or music studios are experiencing a generational transition from old to digitalized goods. However, e-book sales for the fourth quarter of 2010 were only $7 \%$ of all book purchases, according to a study by BISG [33]. The proportion of record companies' global revenues from digital channels was only $29 \%$, according to an IFPI digital music report 2011 [26]. Companies face a dynamic problem of technology adoption, for instance with the slow 
adoption of digital technologies by cable operators and textbook publishers.

Once a firm decides to enter the digital content market, it has to invest in new technology and offer related services. It must also consider whether the digital content market may take a bite out of its entrenched market in physical goods, as consumer preferences shift to less costly digital products. In addition, firms face a chasm between the physical and digital markets as the digitalized content itself becomes increasingly difficult to protect; the value in the digital content market is no longer that of tangible artifacts such as books or CDs. The new market created by digital technology is not just a direct channel via the Internet. The digital content market becomes a service business of providing speed, reliability, and ease of access, rather than a product business [13]. Therefore, firms who are deciding to adopt emerging technology for a digital content market have to make complex decisions loaded with high uncertainty stemming from new technology, intellectual property, and new business model issues, and take into account the abovementioned characteristics of technological investment, market differentiation, and uncertain profitability before adopting the new technologies.

\subsection{Problems and motivations}

As the emerging Internet and digital technology creates new market opportunities, firms face the problem of balancing the risk of rushing into the new market with high technology investment costs, potential losses from cannibalizing existing business, and the uncertainty occurring in the emerging market. The analysis and development of new digital market strategies is gaining attention. Extensive research has been conducted on strategy analysis comparing the physical and digital markets from the view of channel competition $[3,9,10,15,48,50]$. Most of the previous papers have focused on the pricing factor of channel coordination [3, 19] or multiple channel competition strategy of the same tangible product [10, 47]. However, comparatively little attention has been given to the business strategy development of the transformation process from a traditional physical market to a heterogeneous digital market, and discussion of strategic interactions has been relatively rare. In particular, how market interactive and technological parameters affect the business strategies of adopting emerging technologies and entering the new market has not been systematically analyzed yet.

Emerging technologies develop rapidly, and managers constantly face adoption decisions. There are a variety of models in the theoretical literature addressing the problem of new technology adoption. Some studies focus primarily on analyzing the timing of technology adoption, with cost reduction as the main concern [16, 36, 37, 39]. These papers incorporate strategic interactions into the adoption decision; however, they only consider one market structure characterized by homogeneous products and competition in quantities and prices. Other research incorporates both uncertainty and strategic interactions into the decision process [21, 23-25, 27, 43, 51]. Alternatively, some researchers investigate the issue of technology adoption from the demand side (users) point of view [2, 11, 30].

In this research, we focus on the issues of strategic technology adoption and new market entry decisions of the providers in the digital market, which has distinct operational and economic properties and where value creation of the digitized content is the main concern. Specifically, we analyze the strategic interactions between asymmetric players (traditional and digital vendors) by considering market factors (channel cannibalization, new market, and market uncertainty) and technological factors (technology cost, information asymmetry) comprehensively and examine the impact of the brand power of a firm (proxied by market share) on the technology adoption decision. Instead of studying the pricing issue with respect to different market structures, we examine the issue of strategic adoption from the view of a macro market, which allows us to calibrate and compare adoption strategies in various market settings.

The research questions are: First, in what market environment conditions will the outcome of firm's emerging technology adoption is stable (predictable) or uncertain (unpredictable)? Second, what is the impact of a firm's brand power on the adoption outcome and tendency? Third, what are the impacts of technology cost and channel cannibalization on the adoption pattern? Fourth, what happens to the adoption decisions if firms have asymmetric information regarding the cost of the emerging technology and if the new market is uncertain?

\subsection{Contributions and findings}

In this research, we will attempt to answer the above questions by means of game theoretic models to examine the strategic responses of the competing firms. To summarize briefly, our study provides a new model for analyzing firm-level strategic interactions of technology adoption. Using this model, the market conditions for various possible adoption outcomes, which may be stable (single or multiple Nash equilibria) or unstable (mixed strategy equilibrium), are identified and their impacts are comprehensively analyzed. While the impact of factors on the resulting stable adoption outcome may be intuitive, the impact of factors on the adoption tendency (mixed adoption strategy) in the absence of a stable adoption outcome is quite subtle, due to the conflicting competition forces of two firms. 
We obtained a number of interesting results. First, we find that a firm's technology adoption decision tendency is affected by its opponent's technology cost, but not its own cost in the situation of mixed strategy. Second, the higher (lower) the technology cost, cannibalization ratio, market uncertainty, and brand extension the opponent firm faces, the lower (higher) the probability that the leading firm of the traditional market will enter the new market. Third, the effect of technology cost, cannibalization ratio, and brand extension for the new entrant or the following firm will depend on whether the leading firm's brand equity extension succeeds. In the brand extension scenario, the relationship is positive. However, in the brand counterextension, the relationship is negative.

Fourth, when firms make adoption decisions with asymmetric information in the brand counter-extension scenario, the adoption tendency of a firm is negatively (positively) associated with its own (its opponent's) mean technology cost. However, in the scenario of brand extension, the impact of mean technology cost cannot be explicitly determined. Furthermore, in the brand counterextension scenario, the adoption probability of a firm is positively (negatively) associated with the dispersal degree (variance) of its own technology cost when its equilibrium adoption tendency is low (high). However, under the scenario of brand extension, the impact of the cost dispersal degree (variance) cannot be explicitly determined.

The remainder of this paper is organized as follows: In the next section, we review the literature related to the research. We present the emerging technology adoption framework in Sect. 3. In Sect. 4, we conduct the analysis of strategic technology adoption decisions. We analyze the equilibrium adoption outcomes and tendency in duopoly market conditions. We further discuss the effects of cost information asymmetries and market uncertainty. In Sect. 5, we extend the model to consider the scenario that the market share can be endogenized by marketing or operational efforts. Section 6 provides the discussion of our findings and conclusions, managerial implications, research limitations, and direction for future studies.

\section{Related literature}

\subsection{Strategic technology adoption}

Our research on the strategic adoption of emerging technology is related to several streams of theoretical literature, which can be roughly classified into categories depending on whether a model deals with uncertainty factors and/or strategic interactions between competing firms [24]. Reinganum [36, 37] and Fudenberg and Tirole [16] are the seminal works in the field of strategic models with no uncertainty. Reinganum [36, 37] is the first to consider a duopoly market subjected to a single technological advance and to demonstrate that a new technology is diffused over time assuming that firms can pre-commit to specific adoption dates. Fudenberg and Tirole [16] consider a scenario of a duopoly with identical firms that both have the option to upgrade their technology and they demonstrate that the first-mover advantage is not supported by subgame perfect equilibrium strategies if firms are unable to pre-commit to future actions. Riordan [39] introduces governmental regulation into the model of Fudenberg and Tirole [16] in the context of a scenario for cable and telephone companies' adoption decision and finds that regulation can slow the diffusion of technology. This literature only considers market structures with demand certainty for homogeneous products, and the firms compete in quantities enhance their profitability by considering the option of new technology adoption.

Another set of literature incorporates both uncertainty factors and strategic interactions into the decision process. For example, Stenbacka and Tombak [43] extend the framework of Fudenberg and Tirole [16] to an uncertain time period that ranges from the acquisition time to the time of the successful technology implementation. Hoppe [23] integrates uncertainty about the profitability of a technology into the model of Fudenberg and Tirole [16]. Once the technology is adopted, the true value of the technology is revealed to both firms. The second mover (wait and see) will achieve a higher payoff than the leader due to the informational advantage. Huisman and Kort [25] provide a framework where firms take into account future technological improvements in making their technology adoption decision and they find that the possible occurrence of a new technology could turn a preemption game into a war of attrition in which the second mover gets the highest payoff. Zhu and Weyant [51] focus on a two-stage adoption game between two competing firms and explore the strategic decisions of a new technology adoption where there is asymmetric information, and they show that having better information is not always a good thing. Several authors analyze the relationship between market structure and the timing of technology adoption in the presence of network externalities [28-30] and they find firms are more likely to adopt the existing technology early due to network externalities, though the future technology might prove to be superior to the current one.

In this research, we also investigate the issue of adoption decisions with asymmetric information and new market uncertainty, unlike most of the previous works, which mainly focus on the specific parameterization and the market structures with homogeneous product competition. In a digital content market, the purpose of new technology adoption is mainly to provide a new service, instead of 
reducing the cost of producing the existing products. Our work analyzes the strategic technology adoption of competing content providers and predicts the market situations that determine whether a firm will adopt an emerging technology and enter a new market.

\subsection{New channel adoption for the physical product}

With the emergence of the Internet as a viable distribution channel, our work is also related to the literature that explores the issues of channel competition and coordination. These works mainly analyze the impact of launching an Internet channel on conventional retailer(s) facing new competition from a direct Internet channel. For instance, Balasubramanian [3] models competition between direct marketers and traditional retailers and focuses on the role of information in a market with multiple channels, showing the strategic implications of the level of information disseminated by the direct marketer and the market coverage as a lever to control competition. Chiang et al. [10] study the design of dual channel supply chains and find that manufacturers can use a direct channel to oppose the retailer's tendency to set prices too high and improve their overall profitability by reducing the degree of inefficiency. Tsay and Agrawal [45] extend the literature on channel coordination to a setting in which the upstream party is at once a supplier to and a competitor of the downstream party. Yao and Liu [48] examine the pricing equilibria between two channels under the Bertrand and the Stackelberg price competition models. Yan and Pei [47] study the strategic role of the retail services in a dual-channel supply chain. Recently, Yoo and Lee [49] extend Balasubranian's model and identify five key strategic forces that shape the overall impact of an Internet channel introduction. These papers have explored consumer channel choice in commodity markets and the coordination strategy of retailing the same tangible product, modeling the decision as a trade-off between online disutility and search costs, offline transportation costs, in addition to the price differences across the two channels. In our research, we model both the internal and external channel competition effects and study how the technological and market factors affect the process of the transformation from a traditional physical market to a new digital market in a competitive market.

Previous research which examines the impact of a firm's brand and market power on the technology adoption and the decision to enter a new channel includes studies by Cheng and Nault [9], Forman et al. [15], and Brynjolfsson et al. [7]. Cheng and Nault study the internet channel entry decisions of an existing retailer and a new entrant and analyze how the existing market power and coverage affects the outcome of the entry game. Forman et al. empirically examine the consumer substitution between online and offline channels and provide empirical supports and explore how offline geographic location affects the online channel. Brynjolfsson et al. examine the effect of the existing retail market coverage on the outcome of the entry decision. As shown in the above literature review, these works study the adoption decision with respect to different existing market structures and lack any exploration of the impact of brand power extension. In our research, we examine the impact of brand power extension from the view of a macro market, which allows us to calibrate and compare adoption strategies in various market settings.

\subsection{New channel adoption for the digital goods}

Another stream of literature relevant to our study is on strategic technology and new channel adoption in the digital goods market. A number of studies explore cannibalization versus the complementary nature of physical and digital goods. A few studies attempt to directly measure the cannibalization effect of digital distribution on physical channel sales. Deleersnyder et al. [14] survey a sample of 85 internet channel additions over the last 10 years in the newspaper industries of the UK and The Netherlands, and they find that the online digital content has only a small impact on physical newspaper sales. Likewise, Biyalogorsky and Naik [4] find that Tower Records' Internet sales did not significantly cannibalize its retail sales. Waldfogel [46] used survey data on video distribution to show that authorized YouTube viewing of television content has only a small net substitution effect on over-the-air viewing.

Several studies have been done regarding the impact of digital channel distribution on the digital experience goods industry. Chellappa and Shivendu [8] analyzed supply chain coordination contracts in digital supply chains. Smith and Telang [41] study the impact of movie broadcasts and piracy on DVD demand and find no impact of piracy on DVD sales for catalogue titles. Jeong and Khouja [28] develop a model for analyzing the impacts of piracy and supply chain contracts on the performance of supply chains for the digital experience goods. Danaher et al. [12] finds a strong substitution between legitimate digital channels and piracy channels for television content. Smith and Telang [42] find that increased broadband penetration leads to a significant increase in DVD sales. Jiang and Katsamakas [29] have examined how the entry of an e-book seller affects book markets and impacts sellers and consumers.

These papers focus mainly on the coordination issue of digital and physical channel competition. In our research, we predict the outcomes of technology adoption by analyzing the market situations, and we analyze their impact on the tendency to enter the new market when the market has no stable adoption outcome and only mixed adoption strategies are available. 


\section{The model}

\subsection{Emerging technology adoption framework}

We consider a digital content service market in which traditional content providers are facing a transformation decision due to the emergence of new digital technology. At the same time, the potential emerging digital content market is also attracting new firms or other competitors to enter the new market. According to the evidence from the industry, the number of the main firms involved in new market competition for the emerging digital content service is generally limited due to the vast technology investment required. For example, DVD online retailer Amazon and Google faced the decision whether to adopt on-line video services in 2006. In publishing, the e-book market is mainly composed of Amazon's Kindle, Apple's iPad, and Barnes and Noble's Nook. Therefore, in this research, we consider two digital content providers in the market. Another motivation for adopting a duopolistic model is that, when the number of competing firms is limited; their interaction becomes even more strategic; thus we will further analyze competitive strategy in various market environment settings. Figure 1 depicts the proposed adoption framework of the new digital content services.

The traditional market $\Theta_{T}$ is divided into two major players, firm $A$ and firm $B$ with market share $\alpha$ and $1-\alpha$, where $\alpha>0.5$. That is, firm $A$ is the leading brand in the traditional market. Note that if $\alpha=1$, firm $A$ becomes a monopolistic service provider in the traditional market and $B$ is a new company. When the new digital content market is emerging, firm $A(B)$ must decide whether to adopt the new service technology. Owing to the fact that the digital content can be reproduced at little or no cost, we only count the fixed technology investment cost $C_{A}\left(C_{B}\right)$ for firm $A(B)$ and assume that the variable cost of content service provision is negligible. We will relax this assumption of zero marginal cost when we discuss the impact of market uncertainty later in this article.

There is a cannibalization effect as the firm adopts new content service; a ratio $\delta$ of traditional market revenue is transferred to the new market $(0 \leqq \delta \leqq 1)$. Specifically, we assume that the potential new market value is denoted as $\Theta_{N}$ which includes the revenue $\delta \Theta_{T}$ from the users who are transferred from the traditional market. The market share of firms $A$ and $B$ is $\eta$ and $1-\eta$. Notice that, for simplicity, the values of the traditional and the new markets $\Theta_{T}$ and $\Theta_{N}$ can be interpreted as the aggregate revenues the firms can gain from these markets. Parameters $\alpha$ and $\eta$ can be used to represent the brand strength of the firms in the traditional and new content service markets. To develop interesting and meaningful business implications, we consider two important market scenarios to analyze the effects of market parameters on the emerging technology adoption decision. In the first scenario, we assume that the brand power of the leading firm in the traditional market can be successfully extended to the new market. We call this scenario the brand extension scenario (high $\alpha$ and high $\eta, \alpha>0.5, \eta<0.5)$. In the other case, the brand power of the leading firm in the traditional market cannot be extended to the new market. We call this case a brand counter-extension scenario (high $\alpha$ and low $\eta, \alpha>0.5$, $\eta<0.5)$. The smaller company in the traditional market or a new (startup) company (firm $B$ ) dominates the new market even when the big traditional company enters the new market.

The notation for the adoption framework is outlined in Table 1.

\subsection{Profit functions of the service providers}

According to the adoption framework, the profits for firms $A$ and $B$ under various strategic adoption decisions can be represented and summarized as in Table 2.

Fig. 1 Framework of the digital content market

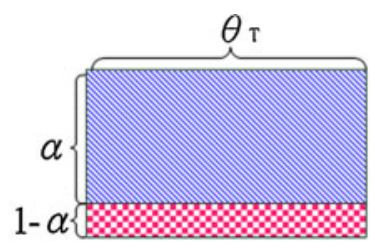

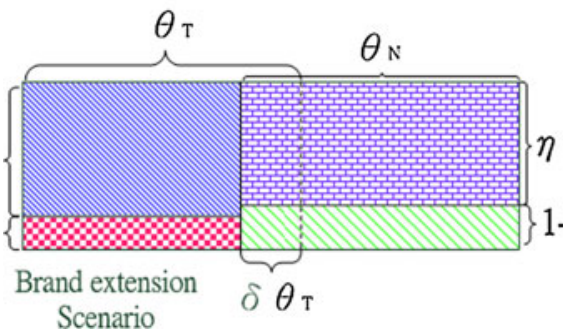

Scenario

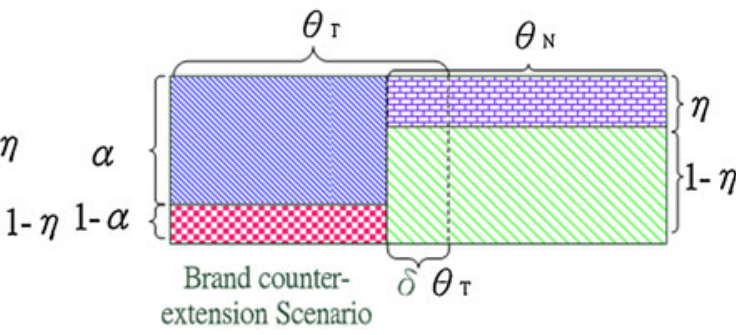


Table 1 Model Parameters

\begin{tabular}{ll}
\hline Notation & Description \\
\hline$\Theta_{T}$ & Aggregate traditional service market value \\
$\Theta_{N}$ & Aggregate new service market value \\
$\alpha$ & The market share of firm $A$ in traditional service market, $0 \leqq \alpha \leqq 1$ \\
$\delta$ & Cannibalization effect; the ratio of value transferred from traditional to new market $0 \leqq \delta \leqq 1$ \\
$\eta$ & The market share of firm $A$ in new service market, $0 \leqq \eta \leqq 1$ \\
$C_{A}\left(C_{B}\right)$ & Technology investment for firm $A(B)$ \\
$\pi_{A}\left(\pi_{B}\right)$ & The profit of firm $A(B)$ \\
$\gamma_{A}\left(\gamma_{B}\right)$ & The probability that the firm $A(B)$ adopt the new service model
\end{tabular}

Table 2 Profits for firm $A(B)$

\begin{tabular}{lll}
\hline Firm $A$ & Firm $B$ & \\
\cline { 2 - 3 } & $\begin{array}{l}\text { Adopt emerging } \\
\text { technology-(I) }\end{array}$ & $\begin{array}{l}\text { Don't adopt emerging } \\
\text { technology-(N) }\end{array}$ \\
\hline Adopt emerging technology-(I) & $\pi_{A}^{I I}, \pi_{B}^{I I}$ & $\pi_{A}^{I N}, \pi_{B}^{I N}$ \\
Don't adopt emerging technology-(N) & $\pi_{A}^{N I}, \pi_{B}^{N I}$ & $\pi_{A}^{N N}, \pi_{B}^{N N}$ \\
\hline
\end{tabular}

If firms $A$ and $B$ both provide the new services:

$$
\begin{aligned}
& \pi_{A}^{I I}=\alpha(1-\delta) \Theta_{T}+\eta \Theta_{N}-C_{A}, \\
& \pi_{B}^{I I}=(1-\alpha)(1-\delta) \Theta_{T}+(1-\eta) \Theta_{N}-C_{B} .
\end{aligned}
$$

If firm $A$ adopts and $B$ does not adopt the new services:

$\pi_{A}^{I N}=\alpha(1-\delta) \Theta_{T}+\Theta_{N}-C_{A}$,

$\pi_{B}^{I N}=(1-\alpha)(1-\delta) \Theta_{T}$.

If firm $A$ does not provide and $B$ does provide the new services:

$\pi_{A}^{N I}=\alpha(1-\delta) \Theta_{T}$,

$\pi_{B}^{N I}=(1-\alpha)(1-\delta) \Theta_{T}+\Theta_{N}-C_{B}$.

If neither firm $A$ nor firm $B$ provides the new services:

$\pi_{A}^{N N}=\alpha \Theta_{T}$

$\pi_{B}^{N N}=(1-\alpha) \Theta_{T}$

\section{Analysis of strategic technology adoption decision}

\subsection{Analysis of strategic adoption outcomes}

First, we focus on conditions for various pure strategic Nash equilibria. If the Nash equilibrium outcome falls into (I, I), that is, both firms $A$ and $B$ adopt a new service, then the following two conditions must be satisfied: $\pi_{A}^{I I}>\pi_{A}^{N I}$ and $\pi_{B}^{I I}>\pi_{B}^{I N}$. On the other hand, if the Nash equilibrium outcome is (I, N), that is, firm $A$ adopts the new service but firm $B$ does not adopt, then the conditions $\pi_{A}^{I N}>\pi_{A}^{N N}$ and
$\pi_{B}^{I N}>\pi_{B}^{I I}$ must simultaneously hold. Similarly, the equilibrium conditions for the situation that firm $A$ does not adopt the new service but firm $B$ adopts (N, I) are $\pi_{A}^{N I}>\pi_{A}^{I I}$ and $\pi_{B}^{N I}>\pi_{B}^{N N}$. Finally, if neither firm adopts the new service $(\mathrm{N}, \mathrm{N})$, then conditions $\pi_{A}^{N N}>\pi_{A}^{I N}$ and $\pi_{B}^{N N}>\pi_{B}^{N I}$ should be satisfied. Consequently, we have the following result.

Proposition 1 (Pure Nash equilibrium) The market environments for various outcomes of adoption decisions by firms $A$ and $B$ are:

(Adoption decision of firm A, Adoption decision of firm $B)=$

$\begin{cases}(\mathrm{I}, \mathrm{I}) & \text { if } \Theta_{N}>\max \left\{C_{A} / \eta, C_{B} /(1-\eta)\right\} \\ (\mathrm{I}, \mathrm{N}) & \text { if } C_{A}+\alpha \delta \Theta_{T}<\Theta_{N}<C_{B} /(1-\eta) \\ (\mathrm{N}, \mathrm{I}) & \text { if } C_{B}+\delta(1-\alpha) \Theta_{T}<\Theta_{N}<C_{A} / \eta \\ (\mathrm{N}, \mathrm{N}) & \text { if } \Theta_{N}<\min \left\{C_{A}+\alpha \delta \Theta_{T}, C_{B}+(1-\alpha) \delta \Theta_{T}\right\}\end{cases}$

From Proposition 1, we observe that both firms will provide the new service when the new market is sufficiently large. If the new market is too small, then neither firm will provide the new service. If the new market is neither too large nor too small, only one of two firms might provide the new service. In addition, the channel cannibalization effect will discourage the firms from entering the new market. However, the degree of asymmetric brand power in the traditional market will encourage the firm with a smaller brand but discourage the firm with a larger brand to enter the market. Note that in some market environments, there could be multiple pure 
Nash equilibria or no pure Nash equilibrium at all, as we will show below.

Figure $2\left(C_{A}=C_{B}, \alpha>0.5\right)$ depicts the configurations of the two firms' equilibrium adoption decision with regard to the new market size $\Theta_{N}$ and the emerging market share of the leading firm $\eta$. We can observe that, as new market size $\Theta_{N}$ increases, at least one of the two firms will provide the new service. When a firm gains a sufficient new market share, this will push the firm to adopt the emerging technology. Otherwise, one of the two firms will decline the new market opportunity. It is worth noting that there is an interesting area $\mathrm{X}$ that has no stable pure strategy Nash equilibrium outcome. In this area, where $\eta \geq 0.5$, only the mixed strategy Nash equilibrium exists. In this situation, a corporation has no clear adoption decision and only a mixed adoption strategy is utilized.

Figure $3\left(C_{A}=C_{B}, \alpha, \eta>0.5\right)$ exhibits the equilibrium adoption configurations of the two firms based on the new market size $\Theta_{N}$ and the emerging technology cost. As shown in the figure, the higher investment cost will impede the adoption of new technology. When the investment cost is low and the new market is large enough, both firms will enter the new market. Figure 3 also reveals that areas $\mathrm{Y}$

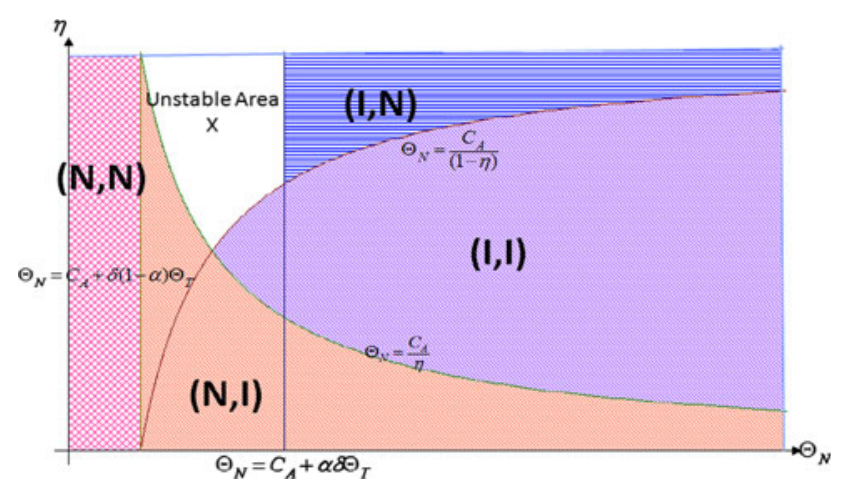

Fig. 2 Adoption configuration of new market size and new market share of the incumbent

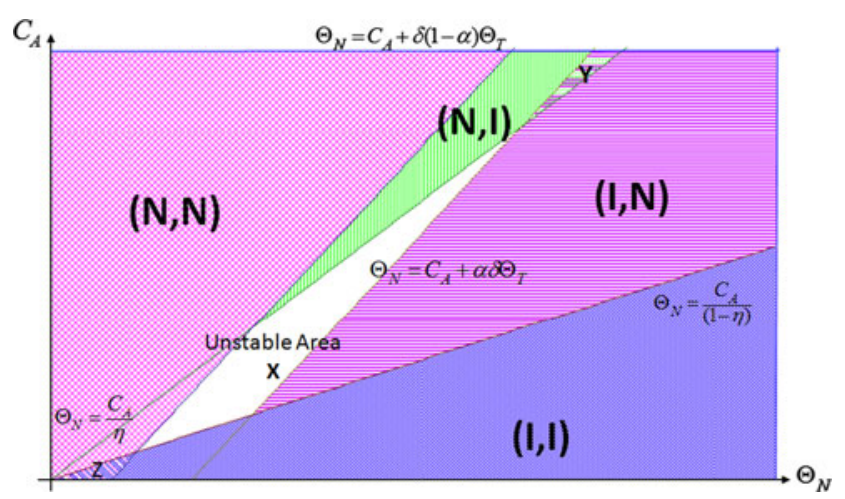

Fig. 3 Adoption configuration of new market size and investment cost of new technology

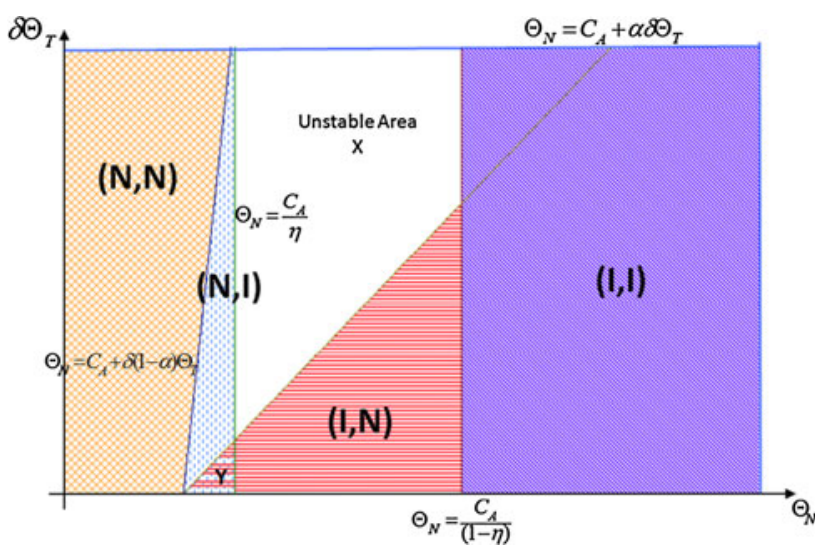

Fig. 4 Adoption configuration with respect to emerging market size and cannibalization ratios of the traditional market

and $\mathrm{Z}$ have two Nash equilibria, and there is also an area $\mathrm{X}$ in which no stable pure strategy equilibrium for the two firms will exist.

Figure $4\left(C_{A}=C_{B}, \alpha, \eta>0.5\right)$ depicts the configuration of the two firms' adoption decision based on the new market size $\Theta_{N}$ and the cannibalization ratio of the traditional market $\delta \Theta_{T}$. There is also an area $\mathrm{X}$ in which there is no stable equilibrium adoption strategy. There exist multiple pure adoption strategy Nash equilibria in area Y.

Corollary 1 (Multiple pure Nash equilibria) The market environment for inducing multiple pure Nash equilibria $(\mathrm{N}, \mathrm{I}),(\mathrm{I}, \mathrm{N})$ is

$$
\begin{aligned}
& \max \left\{C_{A}+\alpha \delta \Theta_{T}, C_{B}+(1-\alpha) \delta \Theta_{T}\right\}<\Theta_{N}<\min \left\{C_{A} / \eta,\right. \\
& \left.\quad<C_{B} /(1-\eta)\right\}
\end{aligned}
$$

and the market environment for inducing multiple pure Nash equilibria $(\mathrm{N}, \mathrm{N}),(\mathrm{I}, \mathrm{I})$ is

$$
\begin{aligned}
& \max \left\{C_{A} / \eta,<C_{B} /(1-\eta)\right\}<\Theta_{N}<\min \left\{C_{A}+\alpha \delta \Theta_{T}, C_{B}\right. \\
& \left.\quad+(1-\alpha) \delta \Theta_{T}\right\} .
\end{aligned}
$$

Corollary 2 (Non-existence of pure Nash equilibrium) In the following market environments, there exists no pure Nash equilibrium (there is only a mixed Nash equilibrium)

$$
\begin{aligned}
& \max \left\{C_{B}+(1-\alpha) \delta \Theta_{T}, C_{A} / \eta\right\}<\Theta_{N}<\min \left\{C_{A}+\alpha \delta \Theta_{T},\right. \\
& \left.\quad C_{B} /(1-\eta)\right\} \text { or } \\
& \max \left\{C_{A}+\alpha \delta \Theta_{T}, C_{B} /(1-\eta)\right\}<\Theta_{N} \\
& \quad<\min \left\{C_{B}+(1-\alpha) \delta \Theta_{T}, C_{A} / \eta\right\} .
\end{aligned}
$$

One can see from Eqs. 10-13 and Figs. 2, 3, 4 that only when the new market is not too large or small can the market environment have multiple and unstable pure Nash equilibria. However, the adoption of new technology in a new market with multiple pure Nash equilibria is greater than in the new market with no pure Nash equilibrium. Specifically, Fig. 2 illustrates that the mixed adoption 
strategy is utilized when the new market share of the dominant traditional market incumbent $\eta$ is high. Figure 3 reveals that the mixed adoption strategy is utilized when the investment cost and the new market revenue are similar. Figure 4 shows that the mixed adoption strategy is exploited in the area where the cannibalization ratio is high.

Note that, in a static game setting, the outcome of multiple Nash equilibria will be dependent on some coordination protocols. In a dynamic game setting, the outcome can be predicted by the move sequence of the players. For example, assume (I, N) and (N, I) are the two multiple Nash equilibria. The outcome of Subgame Perfect Nash Equilibrium (SPNE) can be predicted as follows: if the first-mover firm enters the new market, then the second mover will not enter. Similarly, if the first-mover does not enter the new market, then the second firm will enter. Note that the outcome of SPNE will be the same as the outcome of the Nash equilibria if there is only a single pure strategy Nash equilibrium outcome.

\subsection{Analysis of strategic adoption tendency}

After discussing the pure strategies of firms $A$ and $B$, we find that there are areas with no stable pure strategy equilibrium. Therefore, we turn our focus to the strategic technology adoption tendency in which the adoption decisions of two firms are uncertain. The adoption tendency can be measured by the probability that a firm adopts an emerging technology that is required to provide the new digital content service. In these areas, only mixed strategies equilibria exist and the outcome of the adoption game is stochastic. We denote as $\gamma_{A}$ the probability that firm $A$ adopts the emerging technology and provides the new service, and as $\gamma_{B}$ the probability that firm $B$ will enter the new digital content service market. According to the payoff functions described, the objective of firms $A$ and $B$ is to maximize their own profit. The expected profit functions can be written as:

$$
\begin{aligned}
\max _{\gamma_{A}} E\left(\pi_{A} \mid \gamma_{B}\right)= & \gamma_{A}\left(\gamma_{B} \pi_{A}^{I I}+\left(1-\gamma_{B}\right) \pi_{A}^{I N}\right) \\
& +\left(1-\gamma_{A}\right)\left(\gamma_{B} \pi_{A}^{N I}+\left(1-\gamma_{B}\right) \pi_{A}^{N N}\right) \\
\max _{\gamma_{B}} E\left(\pi_{B} \mid \gamma_{A}\right)= & \gamma_{B}\left(\gamma_{A} \pi_{B}^{I I}+\left(1-\gamma_{A}\right) \pi_{B}^{N I}\right) \\
& +\left(1-\gamma_{B}\right)\left(\gamma_{A} \pi_{B}^{I N}+\left(1-\gamma_{A}\right) \pi_{B}^{N N}\right)
\end{aligned}
$$

Plugging profit functions (1-8) into the Eqs. 14 and 15, we observe that $\pi_{A}$ is a linear function on $\gamma_{A}$ and $\pi_{B}$ is a linear function on $\gamma_{B}$. Comparing the terms in both objective functions, we find that firm $A$ 's best response adoption strategy correspondence to firm $B$ 's provision strategy $\gamma_{B}$ is

$$
\begin{gathered}
\gamma_{A}^{*}\left(\gamma_{B}\right)=\left\{\begin{array}{ll}
1 & \text { if } \gamma_{B}>\hat{\gamma}_{B} \\
{[0,1]} & \text { if } \gamma_{B}=\hat{\gamma}_{B}, \\
0 & \text { if } \gamma_{B}<\hat{\gamma}_{B}
\end{array}\right. \text { where } \\
\hat{\gamma}_{B}=\frac{\left(\Theta_{N}-\alpha \delta \Theta_{T}\right)-C_{A}}{(1-\eta) \Theta_{N}-\alpha \delta \Theta_{T}}
\end{gathered}
$$

Firm $B$ 's best response adoption strategy correspondences to firm $A$ 's strategy $\gamma_{A}$ is

$$
\begin{gathered}
\gamma_{B}^{*}\left(\gamma_{A}\right)=\left\{\begin{array}{ll}
1 & \text { if } \gamma_{A}>\hat{\gamma}_{A} \\
{[0,1]} & \text { if } \gamma_{A}=\hat{\gamma}_{A}, \\
0 & \text { if } \gamma_{A}<\hat{\gamma}_{A}
\end{array}\right. \text { where } \\
\hat{\gamma}_{A}=\frac{\left(\Theta_{N}-(1-\alpha) \delta \Theta_{T}\right)-C_{B}}{\eta \Theta_{N}-(1-\alpha) \delta \Theta_{T}}
\end{gathered}
$$

Solving the above two best response adoption strategy correspondences simultaneously, we have the following result.

Proposition 2 (Mixed strategy Nash equilibrium) The equilibrium tendency of adopting strategies (the probability of providing the new service) of firms $A$ and $B$ is

$$
\left(\gamma_{A}^{*}, \gamma_{B}^{*}\right)=\left(\frac{\left(\Theta_{N}-(1-\alpha) \delta \Theta_{T}\right)-C_{B}}{\eta \Theta_{N}-(1-\alpha) \delta \Theta_{T}}, \frac{\left(\Theta_{N}-\alpha \delta \Theta_{T}\right)-C_{A}}{(1-\eta) \Theta_{N}-\alpha \delta \Theta_{T}}\right),
$$

where $0 \leq \gamma_{A}^{*}, \gamma_{B}^{*} \leq 1$.

(All proofs can be found in the Appendix.)

For analytical convenience, we use representation $G_{1}=$ $\eta \Theta_{N}-(1-\alpha) \delta \Theta_{T}$ and $G_{2}=(1-\eta) \Theta_{N}-\alpha \delta \Theta_{T}$ for the denominators and assume that the brand extension scenario has the characteristic that firm $A$ dominates in both the traditional and new markets (high $\alpha$ and high $\eta$ ) such that the following quantitative conditions are satisfied:

$G_{1}>0$ and $G_{2}<0$.

Equation 19 implies that the brand extension scenario occurs only when the channel cannibalization $\delta \Theta_{T}$ is sufficiently large.

The brand counter-extension scenario has the characteristic that firm $A$ dominates in the traditional market but firm $B$ dominates in the new market (high $\alpha$ but low $\eta$ ) such that the following quantitative conditions are satisfied:

$G_{1}>0$ and $G_{2}>0$.

Equation 20 implies that the brand counter-extension scenario occurs when the channel cannibalization $\delta \Theta_{T}$ is not too large.

Note that in analysis of the strategic adoption tendency, we focus on the market scenario in which a stable pure adoption strategy outcome is not available, but only a mixed adoption strategy Nash equilibrium. In equilibrium, there should be no payoff difference for any of the two competing firms if they choose "to adopt" or "not to 
adopt." Whether a firm will feel better off from adopting a new technology is conditional on the market factors and its opponent's adoption tendency. For a firm to adopt a mixed adoption strategy, the impact of market factors and the impact of its opponent's adoption tendency should be opposite and balanced. Otherwise, a pure adoption strategy becomes a stable outcome.

The improved adoption tendency of a firm will encourage (avoiding cannibalization loss in the traditional market) as well as discourage (diluting the market share on the new market) its opponent's adoption decision. Conversely, the reduced adoption decision of a firm will encourage (expanding the market share in the new market) as well as discourage (avoiding cannibalization loss in the traditional market) its opponent's adoption decision. The impact of firm $A$ 's adoption tendency on firm $B$ 's adoption decision and the impact of firm $B$ 's adoption tendency on firm $A$ 's adoption decision could be different. A higher adoption tendency of firm $A$ always reduces the incentive of firm $B$ to adopt a new technology because the discouraging factor $\left(\eta \Theta_{N}\right)$ always outperforms the encouraging factor $\left((1-\alpha) \delta \Theta_{T}\right)$. In the brand extension scenario, firm B's higher adoption tendency increases firm $A$ 's incentive to adopt a new technology, as the discouraging factor $\left((1-\eta) \Theta_{N}\right)$ is smaller than the encouraging factor $\left(\alpha \delta \Theta_{T}\right)$. However, in the brand counter-extension scenario, the higher adoption tendency of firm $B$ decreases the incentive of firm $A$ to adopt a new technology because the discouraging factor is higher than the encouraging factor.

Corollary 3 (Impact of technology investment cost on the adoption decision)

(i) The adoption tendency of each firm has no relationship with its own technology cost.

(ii) The adoption tendency of firm A (the leading company in the traditional market) is always negatively associated with the technology cost of firm B ( $a$ small company in the traditional market or a startup company in the new market).

(iii) The adoption tendency of firm $B$ is positively (negatively) associated with the technology cost of firm $A$ in the brand extension (brand counterextension) scenario.

Corollary 3 leads to several interesting results. The first one is that when the competition effect is considered, a firm's technology adoption tendency is affected by its opponent's technology cost but not by its own cost. The second is that, regardless of whether firm $A$ will become a leading brand in the new market or not, the higher (lower) the technology cost that the opponent firm $B$ faces, the lower (higher) the probability that firm $A$ will enter the new market. When firm $B$ 's technology cost increases, its potential profit from entering the new market will decrease and the dominant strategy becomes not to provide the new service. As a result, firm $A$ 's tendency to provide the new service has to be reduced such that firm $B$ can benefit more from providing the new service and still have a non-zero tendency to enter the new market.

However, the adoption tendency of firm $B$ is associated with firm $A$ 's technology cost as well as the market settings. In the brand extension scenario, firm $A$ 's new market share of and the cannibalization ratio of the traditional market are relatively large. The larger the adoption tendency of firm $B$, the more benefit firm $A$ can gain from entering the new market, because it can significantly reduce the cannibalization loss. As firm A's technology cost increases, its profit from the new technology adoption market will decrease. To ensure a non-zero equilibrium adoption tendency of firm $A$, the adoption tendency of firm $B$ must increase with its opponent's technology cost. Nevertheless, in the brand counter-extension scenario, the new market share of firm $A$ and the cannibalization ratio of the traditional market are relatively small. The less tendency of firm $B$ to provide the new service decreases, the more benefit firm $A$ can gain from entering the new market because it can significantly improve the revenue generated from the new market. Therefore, in equilibrium, the adoption tendency of firm $B$ decreases with its opponent's technology cost.

Corollary 4 (Impact of channel cannibalization on the adoption decision)

(i) The adoption tendency of firm A is always negatively associated with the channel cannibalization effect (the amount of revenue transferred from the traditional market to the new market).

(ii) The adoption tendency of firm B is positively (negatively) associated with the channel cannibalization effect in the brand extension (brand counterextension) scenario.

As the cannibalization ratio of the traditional market increases, the revenue of the new market coming from the old market increases and the revenue from the new customers decreases. In contrast, the lower cannibalization ratio means that the new market is another blue ocean market and a potentially disruptive opportunity [6], as the prospective customers are not the same as those in the old market. Therefore, a firm will have a greater incentive to adopt the emerging technology. This interesting finding is consistent with previous disruptive innovation studies [6, $18,44]$. As the cannibalization ratio of the traditional market increases, the benefit for firm $B$ from providing a new service diminishes and it tends not to enter the new market in order to save the technology investment cost. 
Therefore, to ensure that firm $B$ still has a non-zero tendency to provide the new service, the adoption tendency of firm $A$ must decrease so as to enhance the benefit firm $B$ will gain from entering the new market.

As the cannibalization ratio of the traditional market increases, the benefit for firm $A$ from providing a new service diminishes. Firm $B$ has to adjust its adoption tendency to improve firm $A$ 's benefit from entering the new market. In the brand extension scenario ( $\eta$ and $\delta$ are relatively large), the greater the technology adoption tendency of firm $B$, the higher the revenue that firm $A$ can gain from providing a new service, due to a significant reduction of cannibalization loss. Therefore, in equilibrium, the adoption tendency of firm $B$ increases with the channel cannibalization effect. In the brand counter-extension scenario ( $\eta$ and $\delta$ are relatively small), the less the technology adoption tendency of firm $B$, the higher the revenue firm $A$ can collect from entering the new market, due to the significant revenue improvement from providing the new service. Therefore, in equilibrium, the adoption tendency of firm $B$ decreases with the channel cannibalization effect.

Corollary 5 (Impact of brand extension on the adoption decision)

(i) The adoption tendency of firm A is always negatively associated with the new market share of firm A.

(ii) The adoption tendency of firm $B$ is negatively (positively) associated with the new market share of firm $A$ in the brand extension (brand counterextension) scenario.

The result that the adoption tendency of leading firm $A$ is negatively associated with its own new market share is counter-intuitive. The rationale can be explained as follows. As the potentially new market share of the leading firm $A$ increases, its opponent's potential profit from the new service will decreases and tend not to enter the market. To ensure firm $B$ has a non-zero adoption tendency, in equilibrium, the leading firm $A$ must become less likely to enter the new market, such that the revenue of firm $B$ from providing the new service can be improved.

As the new market share of firm $A$ increases, its incentive to adopt new technology increases. Firm $B$ has to adjust its adoption tendency to decrease $A$ 's benefit from entering the new market. With the brand extension, the cannibalization effect is large and the value from the new customers is relatively small. This means that most of the new market revenue comes from the switched customers. The smaller the technology adoption tendency of firm $B$, the less pressure firm $A$ will face to provide a new service to avoid cannibalization loss. Therefore, the higher the new market share of firm $A$, the less likely firm $B$ will be to enter the new market in order to ensure that a pure new technology adoption strategy is not the dominant strategy for firm $A$. However, in the brand counter-extension scenario, the cannibalization ratio of the traditional market is small. The new market generally includes a larger number of new users, instead of the switched customers in the traditional market. The larger the technology adoption tendency of firm $B$, the smaller the revenue firm $A$ can gain from providing a new service. Similar to the analysis of firm $A$ 's adoption, the higher the value of firm $A$ 's new market share, the greater the probability that firm $B$ will enter the new market.

\subsection{Strategic adoption with asymmetric information of technology cost}

It is common that there exists asymmetric information when competing firms make decisions. We consider the scenario in which a firm knows its own technology cost while its opponent does not. So the technology cost is private information. We denote $\Phi_{i}\left(C_{i}\right)$ as the cost CDF of firm $i$ 's technology cost $C_{i}, \quad i \in\{A, B\}$. The types of the technology cost distribution functions $\Phi_{i}\left(C_{i}\right)$ are common knowledge. We denote as $s_{i}\left(C_{i}\right)$ the technology adoption decision of firm $i$, given its private information on technology cost $C_{i} \cdot s_{i}\left(\tilde{C}_{i}\right)=1$ represents when firm $i$ decides to provide the new service, but $s_{i}\left(\tilde{C}_{i}\right)=0$ represents when firm $i$ does not provide the new service. We assume that in equilibrium, firm $i$ will adopt the new service when its realized $\tilde{C}_{i}$ is less than a threshold value $\hat{C}_{i}$. The corresponding pure Bayesian Nash equilibrium is described by the following technology adoption strategies:

$s_{i}\left(\tilde{C}_{i}\right)=\left\{\begin{array}{ll}1 & \text { if } \tilde{C}_{i} \leq \hat{C}_{i} \\ 0 & \text { if } \tilde{C}_{i}>\hat{C}_{i}\end{array}, \quad i \in\{A, B\}\right.$.

Consequently, the probability that firm $i \in\{A, B\}$ adopts the technology can be represented as $\Phi_{i}\left(\hat{C}_{i}\right)$. Obviously a firm's adoption probability increases with the threshold $\hat{C}_{i} ; \partial \Phi\left(\hat{C}_{i}\right) / \partial \hat{C}_{i}>0$. Firm $i$ will adopt the new technology if $E\left(\pi_{i} \mid \tilde{C}_{i} \leq \hat{C}_{i} ; \Phi_{j}\left(\hat{C}_{j}\right)\right) \geq E\left(\pi_{i} \mid \tilde{C}_{i}>\hat{C}_{i} ; \Phi_{j}\left(\hat{C}_{j}\right)\right), i \in$ $\{A, B\}$ or equivalently,

$$
\begin{aligned}
& \Phi_{B}\left(\hat{C}_{B}\right) \pi_{A}^{I I}+\left(1-\Phi_{B}\left(\hat{C}_{B}\right)\right) \pi_{A}^{I N} \geq \Phi_{B}\left(\hat{C}_{B}\right) \pi_{A}^{N I} \\
& \quad+\left(1-\Phi_{B}\left(\hat{C}_{B}\right)\right) \pi_{A}^{N N} \\
& \quad \text { if } \tilde{C}_{A} \leq \hat{C}_{A}, \\
& \Phi_{A}\left(\hat{C}_{A}\right) \pi_{B}^{I I}+\left(1-\Phi_{A}\left(\hat{C}_{A}\right)\right) \pi_{B}^{N I} \geq \Phi_{A}\left(\hat{C}_{A}\right) \pi_{B}^{I N} \\
& \quad+\left(1-\Phi_{A}\left(\hat{C}_{A}\right)\right) \pi_{B}^{N N} \\
& \quad \text { if } \tilde{C}_{B} \leq \hat{C}_{B}
\end{aligned}
$$

Note that, in the setting of asymmetric information, the higher the cost for a firm to acquire a new technology, the lower the probability that the firm will provide the new 
service. However, the adoption tendency of a firm with complete technology cost information (e.g., the mixed adoption strategy Nash equilibrium analyzed in Subsect. 4.1) is not associated with its own cost.

Proposition 3 (Pure Bayesian Nash equilibrium) Denote $\Phi_{i}\left(C_{i}\right)$ as the cost CDF of firm i's technology cost $C_{i}, \quad i \in$ $\{A, B\}$. A realized $\tilde{C}_{i}$ is private information to firm $i$. Firm $i$ will adopt the new service if its technology cost $\tilde{C}_{i} \leq \hat{C}_{i}$. The technology adoption decision thresholds $\hat{C}_{i}, \quad i \in$ $\{A, B\}$ are given by solving the following equations simultaneously:

$\hat{C}_{A}=\left(\Theta_{N}-\alpha \delta \Theta_{T}\right)-\Phi_{B}\left(\hat{C}_{B}\right)\left((1-\eta) \Theta_{N}-\alpha \delta \Theta_{T}\right)$

$\hat{C}_{B}=\left(\Theta_{N}-(1-\alpha) \delta \Theta_{T}\right)-\Phi_{A}\left(\hat{C}_{A}\right)\left(\eta \Theta_{N}-(1-\alpha) \delta \Theta_{T}\right)$

In the following, we analyze the impact of asymmetric cost information on the firm's adoption tendency. For analytical convenience, we assume technology cost functions $\Phi_{i}\left(C_{i}\right), \quad i \in\{A, B\}$ follow the normal distribution $N\left(\mu_{i}, \sigma_{i}^{2}\right)$. We first analyze the impact of the mean of technology cost $\mu_{i}$ on the adoption decision, and then examine the impact of the variance of technology cost $\sigma_{i}^{2}$ on the adoption decision.

Corollary 6 (Impact of mean technology cost on the adoption decision) In the counter-extension scenario, the adoption probability of a firm is negatively (positively) associated with its own (its opponent's) mean technology cost. Formally, $\partial \Phi_{i}\left(\hat{C}_{i}\right) / \partial \mu_{i}<0, \quad \partial \Phi_{j}\left(\hat{C}_{j}\right) / \partial \mu_{i}>0, \quad i \neq$ $j \in\{A, B\}$. However, in the brand extension scenario, the impact of mean technology cost cannot be explicitly determined.

In the counter-extension scenario, $\partial \Phi_{j}\left(\hat{C}_{j}\right) / \partial \Phi_{i}\left(\hat{C}_{i}\right)<0$, for $i \neq j \in\{A, B\}$ always holds. As the mean of a firm's technology cost becomes larger, it becomes less profitable for the firm to provide the new service and, calculating this phenomenon, its opponent, on the contrary, will have a greater incentive to provide the new service. However, in the extension scenario, the sign of $\partial \Phi_{j}\left(\hat{C}_{j}\right) / \partial \Phi_{i}\left(\hat{C}_{i}\right)$ cannot be determined. Therefore, the impact of mean technology cost on the firms' adoption decision could be positive or negative.

Corollary 7 (Impact of technology cost variance on the adoption decision) In the brand counter-extension scenario, ( $i$ ) the adoption probability of a firm is positively (negatively) associated with the dispersion degree (variance) of its own technology cost when its equilibrium adoption tendency is low (high). (ii) the impact of the technology cost disperse degree on it opponent's adoption decision is opposite. Formally, $\partial \Phi_{i}\left(\hat{C}_{i}\right) / \partial \sigma_{i}>0, \partial \Phi_{j}$ $\left(\hat{C}_{j}\right) / \partial \sigma_{i}<0$ for $\hat{C}_{i}<\mu_{i}$ and $\partial \Phi_{i}\left(\hat{C}_{i}\right) / \partial \sigma_{i}<0, \partial \Phi_{j}\left(\hat{C}_{j}\right) /$ $\partial \sigma_{i}>0$ for $\hat{C}_{i}>\mu_{i} j \neq i \in\{A, B\}$. However, in the brand extension scenario, the impact of the cost dispersion degree (variance) cannot be explicitly determined.

As the technology cost becomes more dispersed, the probability that a firm has a smaller or larger technology cost value increases. Therefore, a firm becomes more (less) likely to provide the new service when the original threshold $\hat{C}_{i}$ of a firm is small (large). In the counterextension scenario, calculating this phenomenon, the competing firm, on the contrary, makes the opposite strategy adjustment. The reasons that the effect of cost dispersion degree (variance) on the firms' adoption decision cannot be explicitly determined are similar to those analyzed in Corollary 6.

\subsection{Strategic adoption with market uncertainty}

In the above analyses, we assume the marginal cost for providing content service is negligible. In order to analyze the impact of new market uncertainty, we relax this assumption and include the marginal cost $c$ for content service provision. There are many market scenarios in which the marginal cost $c$ has to be considered. For example, the marginal cost $c$ can be a royalty fee, which has to be paid to the content owners, or the network bandwidth cost incurred to deliver the digital content to the users under some service level agreement (SLA) contract. From the point of view of practice, we assume that the loyalty fee and the quantity of usage rights have to be contracted or the bandwidth capacity has to be allocated before the demand is realized. The demand of the new content service $D$ is stochastic. We denote $\Phi_{D}$ as the CDF of the new market demand $D$ with mean $E(D)$ and variance $\sigma_{D}^{2} . R(d)$ is defined as the revenue for providing content service to $d$ users. Consequently, the expected revenue of the new market can be formulated as:

$\Theta_{N}=\max _{q} \int_{0}^{\infty}(R(\min (D, q))-c q) d \Phi_{D}$.

Note that if $c=0 \quad \Theta_{N}=R(E(D))$ as the optimal quantity $q$ value is infinite due to the zero marginal cost in content provision. That is, the impact of new market uncertainty on the firms' adoption tendency becomes increasingly significant when the marginal cost becomes large and non-negligible. From (26), we have $\partial \Theta_{N} / \partial c<0$ and $\partial \Theta_{N} / \partial \sigma_{D}<0$. The expected market value of the new market decreases with the uncertainty degree of the new market. 
Corollary 8 (Impact of new market uncertainty on the adoption decision)

(i) The adoption tendency of firm A is always negatively associated with the uncertainty degree of the new market.

(ii) The adoption tendency of firm B is positively (negatively) associated with the uncertainty degree of the new market in the brand extension (brand counterextension) scenario.

It is intuitive that firms will have a greater incentive to provide new services if the value of the new market increases. As the market uncertainty will reduce the market value, firm $B$ will tend not to enter the new market if the degree of market uncertainty increases. Firm $B$ 's benefit from entering the new market increases as the adoption tendency of firm $A$ decreases. Therefore, to ensure a nonzero adoption tendency of firm $B$, the adoption tendency of firm $A$ must become smaller to increase the adoption incentive of firm $B$.

In the brand extension scenario, the market share of firm $A$ and the cannibalization ratio of the traditional market are relatively large. If the adoption tendency of firm $B$ increases, firm $A$ benefits more from also entering the new market because it can significantly reduce the cannibalization loss. Since the revenue of firm $A$ from providing the new service decreases with the degree of uncertainty of the new market, firm $B$ 's adoption tendency increases with the degree of uncertainty of the new market. However, in the brand counter-extension scenario, firm $A$ 's market share and the cannibalization ratio of the traditional market are relatively small. If firm $B$ 's adoption tendency to provide the new service decreases, firm $A$ has a greater incentive to enter the new market, because firm $A$ 's marginal benefit from providing the new service is significantly improved. Therefore, the adoption tendency of firm $B$ decreases with the degree of market uncertainty.

\section{Extended model: endogenous new market share}

In the previous section, the new market share of a firm is treated as an exogenous parameter. In this section, we extend the model to analyze the scenario that the new market share can be endogenously determined. The model is extended to a two-stage game. In the first stage, the competing firms first decide whether or not to enter the new market. If firm $i$ decides to enter the new market, it has to acquire the new technology with cost $C_{i}, \quad i \in\{A, B\}$. In the second stage, the firms choose their own marketing effort level to increase the market share. By adopting a backward induction approach, we first analyze the market effort and corresponding equilibrium market share of each firm. Then, with the predicted market shares, we can analyze the firms' decisions on new market entry.

It is reasonable to assume that the new market share is positively associated with the marketing efforts of firm $i$ but negatively associated with those of its opponent firm $j$. Let $e_{i}$ be the marketing effort level of firm $i$ and denote the corresponding cost of marketing effort as $f_{i}\left(e_{i}\right)$.

The market share of firm $i$ can be represented as:

$s_{i}\left(e_{i}, e_{j}\right)=\frac{g\left(e_{i}, \alpha_{i}\right)}{g\left(e_{i}, \alpha_{i}\right)+g\left(e_{j}, \alpha_{j}\right)}, \quad i, j \in\{A, B\}, \quad i \neq j$,

where $g\left(e_{i}, \alpha_{i}\right)$ is the marketing effect of firm $i$ with $\partial g\left(e_{i}, \alpha_{i}\right) / \partial e_{i}>0$ and $\partial g\left(e_{i}, \alpha_{i}\right) / \partial \alpha_{i}>0$. The profitmaximizing problem for firm $i$ can be formulated as:

$\max _{e_{i}} \pi_{i}=s_{i}\left(e_{i}, e_{j}\right) \Theta_{N}-f\left(e_{i}\right), \forall i \neq j \in\{A, B\}$.

Solving $\partial \pi_{i} / \partial e_{i}=0, \forall i \in\{A, B\}$ simultaneously, we have

$\frac{\partial g\left(e_{i}, \alpha_{i}\right) / \partial e_{i} \cdot g\left(e_{j}, \alpha_{j}\right)}{\left(g\left(e_{i}, \alpha_{i}\right)+g\left(e_{j}, \alpha_{j}\right)\right)^{2}}=\frac{\partial f_{i}\left(e_{i}\right)}{\partial e_{i}}, \quad \forall i \neq j \in\{A, B\}$.

For example, we formulate $g\left(e_{i}, \alpha_{i}\right)=e_{i}+\theta \alpha_{i}, \forall i \in$ $\{A, B\}$ and rewrite (29) as

$\frac{e_{j}+\theta \alpha_{j}}{\left(e_{i}+e_{j}+\theta\right)^{2}}=\frac{\partial f_{i}\left(e_{i}\right)}{\partial e_{i}}, \quad \forall i \neq j \in\{A, B\}$.

According to the above two equations, we can further achieve the optimal marketing effort levels of the two firms as:

$e_{i}^{*}=\frac{\partial f_{j}\left(e_{j}\right)}{\partial e_{j}} /\left(\frac{\partial f_{i}\left(e_{i}\right)}{\partial e_{i}}+\frac{\partial f_{j}\left(e_{j}\right)}{\partial e_{j}}\right)^{2}-\alpha_{i} \theta$,

$\forall i \neq j \in\{A, B\}$.

Consequently, the resulting equilibrium new market shares for firm $A$ and firm $B$ are given by:

$\eta^{*}=s_{A}=\frac{\partial f_{B}\left(e_{B}\right) / \partial e_{B}}{\partial f_{A}\left(e_{A}\right) / \partial e_{A}+\partial f_{B}\left(e_{B}\right) / \partial e_{B}}, \quad$ and

$1-\eta^{*}=s_{B}=\frac{\partial f_{A}\left(e_{A}\right) / \partial e_{A}}{\partial f_{B}\left(e_{B}\right) / \partial e_{B}+\partial f_{A}\left(e_{A}\right) / \partial e_{A}}$.

From (32) and (33), we observe that the new market share of a firm increases with its opponent's marginal marketing effort cost but decreases with its own marginal marketing effort cost. Notice that in this research, we assume firms make entry decisions in the first stage and make then make marketing efforts in the second stage if both firms have decided to enter the new market. 


\section{Discussion and conclusion}

In this research, we developed game theory models to analyze the strategic technology adoption decisions of two competing content providers: an existing leading firm in the traditional content market and a new entrant or a firm with smaller brand strength in the traditional market. We analyzed how the market and technological environments (brand power, channel cannibalization effect, technology cost, information asymmetry and market uncertainty) affect the outcome of the emerging technology adoption (new service market entry) game.

We identified the market environment characteristics that will induce various outcomes of the adoption decisions of two asymmetric competing firms. The conditions that predict the outcome of the technology adoption strategy were also analyzed. When the new market (or the technology cost) is not too large or small, the competing firms may only utilize a mixed adoption strategy, in which the adoption tendency is examined. We find that a firm's technology adoption tendency is affected by its opponent's technology cost but not by its own cost. The higher (lower) the technology cost, the cannibalization ratio, the uncertainty degree of the new market, and the brand extension that the opponent firm faces, the lower (higher) the probability that the leading firm of the traditional market will enter the new market. However, the impact of these factors on a firm with smaller brand strength or a new entrant could be the opposite and will depend on the brand equity extension scenarios of the leading firm in the traditional market.

\subsection{Managerial implications}

This research provides a number of managerial implications. First, our model predicts the possible technology adoption outcomes according to various market environment settings. The results indicate that, without considering the market, information, and competition environments, the adoption of emerging technologies and provision of new services cannot be straightforwardly determined. Particularly when the new market and new technology investment are not significantly large or low, the outcomes are very sensitive to the market setting and tend to be stochastic due to the uncertainty of the adoption decision of each firm.

Second, when only a mixed adoption strategy is feasible, the analytical results show that a firm's technology adoption decision is affected by its opponent's technology cost but not by its own cost. This implies that a firm's adoption decision should consider the effect of competition, instead of focusing on the cost a firm faces. The dominant firms in some traditional content industries are trusted for their superior products and distribution of tangible goods, so rapidly shifting to the digital market could threaten their dominance. The leading firms of the traditional media are often reluctant to adopt new technology and to enter the uncertain new market, which may provide a good opportunity for new entrants to offer a new generation of digital products.

The implications may be supported by industry evidence. For example, despite the excitement surrounding the concept of digital textbooks over the past few years, the leading publishers have seen little traction with e-textbook offerings a few years ago because of the high technology cost (immature IT) and small new market (high cannibalization) [17]. Recently, with the rise in open educational resources (the entry of new competitors), the advances in technology related specifically to digital textbooks and the format standard of digital textbooks (the technological cost decreases), publishers have been adopting the digital technology and increasing the availability of digital textbooks for the past 12 months [38].

Third, our findings indicate that the adoption strategy for a smaller (start-up) company is quite sensitive to its relative market dominance in providing a new service. Therefore, an accurate prediction of new market share is important before considering the new service provision.

Fourth, although many marketers consider cannibalization when assessing the potential success of new product introductions [32, 35], there is hardly any knowledge of the impact of channel cannibalization. This study makes a managerial contribution to practitioners by suggesting analysis guidelines on the effect of the cannibalization on the old market.

This implication may be supported by the case of the slow digital adoption of cable operators. Although cable operators face the problem of cord-cutting, the existing cable operators are still reluctant to speed up the adoption of digitalization technology and provide video-on-demand services [1]. The reasons may be as follows: Digitalization of existing cable networks requires large technological investments by the cable operator, and a digital set-top box is required for digital reception. The benefit in terms of the increase in channel capacity is not very valuable to the existing users, and thus the new market is composed of switched customers because of the high cannibalization ratio.

Fifth, this study illustrates the impact of new market uncertainty on the adoption decision. The adoption tendency of the new company is negatively (positively) associated with the uncertainty degree of the new market in the brand extension (brand counter-extension) scenario. This implies that the new entrant's or the following firm's adoption decision should consider whether the leading firm brand equity extension succeeds. 


\subsection{Research contributions}

Our research makes several contributions to academia and industry. From a theoretical perspective, we provide a new theoretical framework which is tied to the actual phenomena we can observe in the digital content market. Compared with existing works, more comprehensive market and technological factors and their interactions (such as competition, information asymmetry, market uncertainty, brand power, channel cannibalization) that will affect the adoption decision are considered in the proposed strategic adoption model. In particular, the market conditions in which adoption decisions of the firms are uncertain and only mixed strategies are feasible are extensively examined. We find that the role of brand power significantly affects the adoption decision of a firm (especially for the start-up company) and several interesting and somewhat counter-intuitive results which are not discussed in existing works are developed.

From a practical perspective, the proposed theoretical model enables practitioners to better understand the adoption of emerging technology in the digital content industry from a more macro view. We also analyzed the possible outcomes of the firms' technology adoption according to these market environments. The results provide useful insights on emerging technology adoption in the digital content industry. The results generated by the proposed model can be used to predict the firms' strategic interactions and corresponding new market configurations. The practical implications of market environment effects also can benefit practitioners by improving their decisionmaking.

\subsection{Limitations and directions for future study}

Several limitations should be noted when applying the theoretical findings of this study to explain the strategic interaction of emerging technology adoption. First, in our theoretical model, we treated the new market profit and cannibalization ratios as exogenous variables. Future work can usefully endogenize those variables into a theoretical model. Second, our analysis framework only analyzes the two highlighted market scenarios (brand extension and brand counter-extension). The analysis extending the two market scenarios could be further explored. In addition, future research can also include other factors (e.g., the externality effect) to analyze the adoption decision. Third, our model applies particularly well to oligopolistic industries where large firms dominate the traditional market. While the presence of more players will have less strategic implications, it is still interesting to analyze the effect of the number and structure of the players on the resulting adoption decision outcomes. Fourth, our analysis is focused on the digital content industries. Future research can extend our model to other industries. Finally, as the results are mainly explored based on analytical models, further relevant empirical studies on digital content technology adoption will be helpful for the validation of the analytical findings.

Acknowledgments The authors would like to thank the two Special Issue Guest Editors, Robert Kauffman and Angsana Techatassanasoontorn, and the four anonymous reviewers for their valuable comments and helpful suggestions, which significantly improve the quality of the paper.

\section{Appendix}

Proposition 1

Proof The conditions for Nash equilibrium outcome (I, I) are $\pi_{A}^{I I}>\pi_{A}^{N I}$ and $\pi_{B}^{I I}>\pi_{B}^{I N}$. That is $\eta \Theta_{N}>C_{A}$ and $(1-\eta)$ $\Theta_{N}>C_{B}$, we have $\Theta_{N}>\max \left\{C_{A} / \eta,<C_{B} /(1-\eta)\right\}$.

The conditions for Nash equilibrium outcome (I, N) are $\pi_{A}^{I N}>\pi_{A}^{N N}$ and $\pi_{B}^{I N}>\pi_{B}^{I I}$. That is $\Theta_{N}-\alpha \delta \Theta_{T}>C_{A}$ and $(1-\eta) \Theta_{N}<C_{B}$, we have $C_{A}+\alpha \delta \Theta_{T}<\Theta_{N}<C_{B} /(1-\eta)$.

The conditions for Nash equilibrium outcome (N, I) are $\pi_{A}^{N I}>\pi_{A}^{I I}$ and $\pi_{B}^{N I}>\pi_{B}^{N N}$. That is $\eta \Theta_{N}<C_{A}$ and $\Theta_{N}-$ $\delta(1-\alpha) \Theta_{T}>C_{B}$. We have $C_{B}+\delta(1-\alpha) \Theta_{T}<\Theta_{N}<$ $C_{A} / \eta$.

The conditions for Nash equilibrium outcome $(\mathrm{N}, \mathrm{N})$ are $\pi_{A}^{N N}>\pi_{A}^{I N}$ and $\pi_{B}^{N N}>\pi_{B}^{N I}$. That is $\Theta_{N}-\alpha \delta \Theta_{T}<C_{A}$ and $\Theta_{N}-(1-\alpha) \delta \Theta_{T}<C_{B}$. We have $\Theta_{N}<\min \left\{C_{A}+\alpha \delta \Theta_{T}\right.$, $\left.C_{B}+(1-\alpha) \delta \Theta_{T}\right\}$.

Corollary 1

Proof The conditions for pure Nash equilibrium adoption strategy $(\mathrm{I}, \mathrm{N}),(\mathrm{N}, \mathrm{I})$ are $C_{A}+\alpha \delta \Theta_{T}<\Theta_{N}<C_{B} /(1-\eta)$ and $C_{B}+\delta(1-\alpha) \Theta_{T}<\Theta_{N}<C_{A} / \eta$ respectively.

Multiple pure Nash equilibra (I,N), (N,I) occur when all the above conditions are satisfied or equivalently,

$$
\begin{aligned}
& \max \left\{C_{A}+\alpha \delta \Theta_{T}, C_{B}+(1-\alpha) \delta \Theta_{T}\right\}<\Theta_{N}<\min \left\{C_{A} / \eta,\right. \\
& \left.\quad<C_{B} /(1-\eta)\right\} .
\end{aligned}
$$

Multiple pure Nash equilibra, (I,I), (N,N) occur when all the above conditions are satisfied or equivalently,

$$
\begin{aligned}
& \max \left\{C_{A} / \eta,<C_{B} /(1-\eta)\right\}<\Theta_{N}<\min \left\{C_{A}+\alpha \delta \Theta_{T}, C_{B}\right. \\
& \left.\quad+(1-\alpha) \delta \Theta_{T}\right\} .
\end{aligned}
$$

Corollary 2

Proof The conditions for the existence of mixed Nash adoption strategy is all the conditions in Eq. 9 are 
not satisfied. (I, I) and (I, N) will not occur if $\Theta_{N}<$ $\min \left(C_{A}+\alpha \delta \Theta_{T}, C_{B} /(1-\eta)\right)$. (N, I) and $(\mathrm{N}, \mathrm{N})$ will not occur if $\Theta_{N}>\max \left(C_{B}+\delta(1-\alpha) \Theta_{T}, C_{A} / \eta\right)$. We have

$$
\begin{aligned}
& \max \left(C_{B}+\delta(1-\alpha) \Theta_{T}, C_{A} / \eta\right)<\Theta_{N}<\min \left(C_{A}+\alpha \delta \Theta_{T},\right. \\
& \left.\quad C_{B} /(1-\eta)\right)
\end{aligned}
$$

Similarly, the other scenario is (I, I) and (I, N) will not occur if $\Theta_{N}<\min \left(C_{B}+\delta(1-\alpha) \Theta_{T}, C_{A} / \eta\right)$. (N, I) and $(\mathrm{N}, \mathrm{N})$ will not occur if $\Theta_{N}>\max \left(C_{A}+\alpha \delta \Theta_{T}, C_{B} /\right.$ $(1-\eta))$. We have $\max \left(C_{A}+\alpha \delta \Theta_{T}, C_{B} /(1-\eta)\right)<$ $\Theta_{N}<\min \left(C_{B}+\delta(1-\alpha) \Theta_{T}, C_{A} / \eta\right)$.

\section{Proposition 2}

Proof The mixed strategy Nash equilibrium is described by both Eqs. 16 and 17 are satisfied. We have $\left(\gamma_{A}^{*}, \gamma_{B}^{*}\right)=\left(\hat{\gamma}_{A}, \hat{\gamma}_{B}\right)$.

\section{Corollary 3}

Proof (i) From (18), we have $\partial \gamma_{i}^{*} / \partial C_{i}=0$ for $i \in$ $\{A, B\} . \quad$ (ii) $\partial \gamma_{A}^{*} / \partial C_{B}=\frac{-\left(\eta \Theta_{N}-(1-\alpha) \delta \Theta_{T}\right)}{\left(\eta \Theta_{N}-(1-\alpha) \delta \Theta_{T}\right)^{2}}<0$ given $G_{1}>0$. (iii) $\frac{\partial r_{B}^{*}}{\partial C_{A}}=\frac{\alpha \delta \Theta_{T}-(1-\eta) \Theta_{N}}{\left(\alpha \delta \Theta_{T}-(1-\eta) \Theta_{N}\right)^{2}}>0$ when $G_{2}<0$ (brand extension), but $\frac{\partial r_{B}^{*}}{\partial C_{A}}<0$ when $G_{2}>0$ (brand counter-extension).

\section{Corollary 4}

Proof (i) Since $0 \leq r_{A}^{*} \leq 1$, we have $(1-\eta) \Theta_{N}-C_{B} \leq 0$ and $\frac{\partial r_{A}^{*}}{\partial\left(\delta \Theta_{T}\right)}=\frac{(1-\alpha)\left((1-\eta) \Theta_{N}-C_{B}\right)}{\left(\eta \theta_{N}-(1-\alpha) \delta \Theta_{T}\right)^{2}} \leq 0$. (ii) Since $0 \leq r_{B}^{*} \leq 1$, we have $\eta \Theta_{N}-C_{A} \leq 0$ when $G_{2}>0$ and $\eta \Theta_{N}-C_{A} \geq 0$ when $G_{2}<0$. Therefore, $\frac{\partial r_{B}^{*}}{\partial\left(\delta \Theta_{T}\right)}=\frac{\alpha\left(\eta \Theta_{N}-C_{A}\right)}{\left(\alpha \delta \Theta_{T}-(1-\eta) \Theta_{N}\right)^{2}} \leq 0$ when $G_{2}>0$ (brand counter-extension) but $\frac{\partial r_{B}^{*}}{\partial\left(\delta \Theta_{T}\right)} \geq 0$ when $G_{2}<0$ (brand extension).

\section{Corollary 5}

Proof (i) Since $r_{A}^{*} \geq 0$ and $G_{1} \geq 0$, we have $\left(\Theta_{N}-(1-\alpha) \delta \Theta_{T}\right)-C_{B} \geq 0$ and $\frac{\partial r_{A}^{*}}{\partial \eta}=\frac{\Theta_{N}\left(C_{B}+(1-\alpha) \delta \Theta_{T}-\Theta_{N}\right)}{\left(\eta \Theta_{N}-(1-\alpha) \delta \Theta_{T}\right)^{2}}$ $\leq 0$. (ii) Since $r_{B}^{*} \geq 0$, we have $\left(\Theta_{N}-\alpha \delta \Theta_{T}\right)-C_{A}>0$ when $G_{2}>0$ (brand counter-extension) and $\left(\Theta_{N}-\right.$ $\left.\alpha \delta \Theta_{T}\right)-C_{A}<0$ when $G_{2}<0$ (brand extension). $\frac{\partial r_{B}^{*}}{\partial \eta}=$ $\frac{\Theta_{N}\left(\Theta_{N}-C_{A}-\alpha \delta \Theta_{T}\right)}{\left(\alpha \delta \Theta_{T}-(1-\eta) \Theta_{N}\right)^{2}}>0$ when $G_{2}>0$ (brand counter-extension) but $\frac{\partial r_{B}^{*}}{\partial \eta}=\frac{\Theta_{N}\left(\Theta_{N}-C_{A}-\alpha \delta \Theta_{T}\right)}{\left(\alpha \delta \Theta_{T}-(1-\eta) \Theta_{N}\right)^{2}}<0$ when $G_{2}<0$ (brand extension).
Proposition 3

Proof Firm A adopts technology when $\tilde{C}_{A} \leq \hat{C}_{A}$. Solving Eq. 22, we obtain

$$
\begin{aligned}
& \Phi_{B}\left(\hat{C}_{B}\right)\left(\alpha(1-\delta) \Theta_{T}+\eta \Theta_{N}-\tilde{C}_{A}\right)+\left(1-\gamma_{B}\right) \\
& \left(\alpha(1-\delta) \Theta_{T}+\Theta_{N}-\tilde{C}_{A}\right) \\
& >\Phi_{B}\left(\hat{C}_{B}\right)\left(\alpha(1-\delta) \Theta_{T}\right)+\left(1-\gamma_{B}\right)\left(\alpha \Theta_{T}\right) .
\end{aligned}
$$

The equation $\tilde{C}_{A} \leq\left(\Theta_{N}-\alpha \delta \Theta_{T}\right)-\Phi_{B}\left(\hat{C}_{B}\right)((1-\eta)$ $\left.\Theta_{N}-\alpha \delta \Theta_{T}\right)=\hat{C}_{A}$ is achieved. Similarly, firm B adopts technology when $\tilde{C}_{B} \leq \hat{C}_{B}$. Solving Eq. 23, we obtain $\Phi_{A}\left(\hat{C}_{A}\right)\left((1-\alpha)(1-\delta) \Theta_{T}+(1-\eta) \Theta_{N}-\tilde{C}_{B}\right)+\left(1-\Phi_{A}\left(\hat{C}_{A}\right)\right)$ $\left((1-\alpha)(1-\delta) \Theta_{T}+\Theta_{N}-\tilde{C}_{B}\right)>\Phi_{A}\left(\hat{C}_{A}\right)\left((1-\alpha)(1-\delta) \Theta_{T}\right)+$ $\left(1-\Phi_{A}\left(\hat{C}_{A}\right)\right)\left((1-\alpha) \Theta_{T}\right)$. We have $\tilde{C}_{B} \leq\left(\Theta_{N}-(1-\alpha)\right.$ $\left.\delta \Theta_{T}\right)-\Phi_{B}\left(\hat{C}_{B}\right)\left(\eta \Theta_{N}-(1-\alpha) \delta \Theta_{T}\right)=\hat{C}_{B}$.

\section{Corollary 6}

Proof (A). Under the scenario of brand counter-extension $\left(G_{2}>0\right)$, from (24) and (25) we have $\partial \Phi_{i}\left(\hat{C}_{i}\right) / \partial \hat{C}_{j}<0$ and $\partial \Phi\left(\hat{C}_{i}\right) / \partial \Phi\left(\hat{C}_{j}\right)<0, \quad i \neq j \in\{A, B\} . \Phi_{i}\left(\hat{C}_{i}\right)$ will become lower as the mean of technology cost becomes higher. As a result, $\Phi_{j}\left(\hat{C}_{j}\right)$ and $\hat{C}_{j}$ becomes higher and $\hat{C}_{i}$ becomes smaller.

(B). Under the scenario of brand extension $\left(G_{2}<0\right)$, we have $\partial \Phi_{A}\left(\hat{C}_{A}\right) / \partial \hat{C}_{B}<0$ and $\partial \Phi_{B}\left(\hat{C}_{B}\right) / \partial \hat{C}_{A}>0$ No matter whether the equilibrium adoption tendency is high or low, a higher disperse degree (variance) of technology cost may increase or decrease the decision threshold for each firm $\hat{C}_{i}, \quad i \in\{A, B\}$. Consequently, the impact of cost disperse on the adoption tendency is unclear.

\section{Corollary 7}

Proof (A). Under the scenario of brand counter-extension $\left(G_{2}>0\right)$, from (24) and (25) we have $\partial \Phi_{i}\left(\hat{C}_{i}\right) / \partial \hat{C}_{j}<$ 0 and $\partial \Phi\left(\hat{C}_{i}\right) / \partial \Phi\left(\hat{C}_{j}\right)<0 \quad i \neq j \in\{A, B\}$. When the equilibrium adoption tendency is low (e.g. $\left.\hat{C}_{i}<\mu_{i}\right), \Phi_{i}\left(\hat{C}_{i}\right)$ will become larger as the disperse degree (variance) of technology cost becomes higher. As a result, $\Phi_{j}\left(\hat{C}_{j}\right)$ and $\hat{C}_{j}$ becomes lower and $\hat{C}_{i}$ becomes larger. On the contrary, if the equilibrium adoption tendency is high (e.g. $\hat{C}_{i}>\mu_{i}$ ), $\Phi_{i}\left(\hat{C}_{i}\right)$ will become smaller as the disperse degree (variance) of technology cost becomes higher. As a result, $\Phi_{j}\left(\hat{C}_{j}\right)$ and $\hat{C}_{j}$ becomes larger and $\hat{C}_{i}$ becomes smaller. 
(B). Under the scenario of brand extension $\left(G_{2}<0\right)$, we have $\partial \Phi_{A}\left(\hat{C}_{A}\right) / \partial \hat{C}_{B}<0$ and $\partial \Phi_{B}\left(\hat{C}_{B}\right) / \partial \hat{C}_{A}>0$. No matter the equilibrium adoption tendency is high or low, a higher disperse degree (variance) of technology cost may increase or decrease the decision threshold for each firm $\hat{C}_{i}, \quad i \in$ $\{A, B\}$. Consequently, the impact of cost disperse on the adoption tendency is unclear.

\section{Corollary 8}

Proof (i) $\partial \gamma_{A}^{*} / \partial \Theta_{N}=\frac{\eta C_{B}-(1-\eta)(1-\alpha) \delta \Theta_{T}}{\left(\eta \Theta_{N}-(1-\alpha) \delta \Theta_{T}\right)^{2}}>0$, given $0 \leq \gamma_{A}^{*}$ $\leq 1$ and $G_{1}>0$. Since $\partial \Theta_{N} / \partial \sigma_{D}<0$, we have $\partial \gamma_{A}^{*} / \partial \sigma_{D}<0$. (ii) Since $\frac{\partial r_{B}^{*}}{\partial \Theta_{N}}=\frac{(1-\eta) C_{A}-\eta \alpha \delta \Theta_{T}}{\left((1-\eta) \Theta_{N}-\alpha \delta \Theta_{T}\right)^{2}}$, we $\frac{\partial r_{B}^{*}}{\partial \sigma_{D}}>0$ when $G_{2}<0$ (brand extension), but $\frac{\partial r_{B}^{*}}{\partial \sigma_{D}}<0$ when $G_{2}>0$ (brand counter-extension).

\section{References}

1. Adda J, Ottaviani M (2005) The transition to digital television. Econ Policy 20(41):160-209

2. Au Y, Kauffman R (2001) Should we wait? Network externalities, compatibility, and electronic billing adoption. J Manage Inform Syst 18(2):47-63

3. Balasubramanian S (1998) Mail versus mall: a strategic analysis of competition between direct marketers and conventional retailers. Market Sci 17:181-195

4. Biyalogorsky E, Naik P (2003) Clicks and mortar: the effect of on-line activities on off-line sales. Market Lett 14(1):21-32

5. Bockstedt JC, Kauffman RJ, Riggins FJ (2006) The move to artist-led on-line music distribution: a theory-based assessment and prospects for structural changes in the digital music market. Int J Electron Commer 10(3):7-38

6. Bower J, Christensen C (1995) Disruptive technologies: catching the wave. Harvard Bus Rev 73:43-53

7. Brynjolfsson E, Hu YJ, Rahman MS (2009) Battle of the retail channels: how product selection and geography drive crosschannel competition. Manage Sci 55(11):1755-1765

8. Chellappa RK, Shivendu S (2003) Pay now or pay later? Managing digital product supply chains. In: International conference on electronic commerce, Pittsburgh, Pennsylvania. ACM, pp 230-234

9. Cheng Z, Nault BR (2007) Internet channel entry: retail coverage and entry cost advantage. Inform Technol Manage 8(2):111-132

10. Chiang WK, Chhajed D, Hess JD (2003) Direct marketing, indirect profits: a strategic analysis of dual-channel supply-chain design. Manage Sci 49:1-20

11. Choi J, Thum M (1998) Market structure and the timing of technology adoption with network externalities. Eur Econ Rev 42(2):225-244

12. Danaher B, Dhanasobhon S, Smith MD, Telang R (2010) Converting pirates without cannibalizing purchasers: the impact of digital distribution on physical sales and internet piracy. Market Sci 29(6):1138-1151

13. Davis R (2001) The digital dilemma. Commun ACM 44(2):77-83

14. Deleersnyder B, Geyskens I, Gielens K, Dekimpe M (2002) How cannibalistic is the Internet channel? a study of the newspaper industry in the United Kingdom and the Netherlands. Int J Res Mark 19(4):337-348

15. Forman C, Ghose A, Goldfarb A (2009) Competition between local and electronic markets: how the benefit of buying online depends on where you live. Manage Sci 55(1):47-57

16. Fudenberg D, Tirole J (1985) Preemption and rent equalization in the adoption of new technology. Rev Econ Stud 52(3):383-401

17. Gallagher S (2002) Key issues to consider in assessing the digital content landscape. ECAR Res Bull 2002(14):1-11

18. Gans J, Stern S (2003) The product market and the market for ideas: commercialization strategies for technology entrepreneurs. Res Policy 32(2):333-350

19. Geyskens I, Gielens K, Dekimpe MG (2002) The market valuation of internet channel additions. J Market 66(2):102-119

20. Global entertainment and media outlook 2010-2014 (2010) PricewaterhouseCoopers. Available at http://www.einnews.com/ pr-news/90509-pricewaterhousecoopers-releases-global-entertain ment-and-media-outlook-2010-2014. Accessed 12 Jun 2011

21. Gotz G (2000) Strategic timing of adoption of new technologies under uncertainty: a note. Int J Ind Organ 18(2):369-379

22. Han JK, Kim N, Kim HB (2001) Entry barriers: a dull-, one-, or two-edged sword for incumbents? Unraveling the paradox from a contingency perspective. J Market 65(1):1-14

23. Hoppe $H$ (2000) Second-mover advantages in the strategic adoption of new technology under uncertainty. Int $\mathbf{J}$ Ind Organ $18(2): 315-338$

24. Hoppe H (2002) The timing of new technology adoption: theoretical models and empirical evidence. Manch Sch 70(1):56-76

25. Huisman K, Kort P (2004) Strategic technology adoption taking into account future technological improvements: a real options approach. Eur J Oper Res 159(3):705-728

26. IFPI. Digital music report. Available at http://www.ifpi.org/sitecontent/library/digital-music-report-2006.pdf. Accessed 12 Jun 2011

27. Jensen $R$ (1982) Adoption and diffusion of an innovation of uncertain profitability. J Econ Theory 27(1):182-193

28. Jeong BK, Khouja M, Zhao K (2011) The impacts of piracy and supply chain contracts on digital music channel performance. Decis Support Syst (in Press)

29. Jiang Y, Katsamakas E (2010) Impact of e-book technology: ownership and market asymmetries in digital transformation. Electron Commer Res Appl 9(5):386-399

30. Katz M, Shapiro C (1986) Technology adoption in the presence of network externalities. J Polit Econ 94(4):822-841

31. Kim C, Oh E, Shin N (2010) An empirical investigation of digital content characteristics, value, and flow. J Comput Inform Syst 50(4):79-87

32. Mason George R, Charlotte H (1994) An approach for identifying cannibalization within product line extensions and multi-brand strategies. J Bus Res 31(2-3):163-170

33. Milliot J, Reid C (2011) It's a digital book world. Available at http://www.publishersweekly.com/pw/by-topic/digital/conferences/ article/45946-it-s-a-digital-book-world.html. Accessed Nov 19 2011

34. Premkumar GP (2003) Alternate distribution strategies for digital music. Comm ACM 46(9):89-95

35. Reddy S, Holak S, Bhat S (1994) To extend or not to extend: success determinants of line extensions. J Market Res 31(2):243-262

36. Reinganum JF (1981) On the diffusion of new technology: a game theoretic approach. Rev Econ Stud 48(3):395-405

37. Reinganum JF (1981) Market structure and the diffusion of new technology. Bell J Econ 12(2):618-624

38. Reynolds R (2011) Trends influencing the growth of digital textbooks in US higher education. Publish Res Q 27(2):178-187

39. Riordan M (1992) Regulation and preemptive technology adoption. Rand J Econ 23(3):334-349 
40. Shapiro C, Varian HR (1999) Information rules: a strategic guide to the network economy. Harvard Business Press, Boston

41. Smith MD, Telang R (2009) Competing with free: the impact of movie broadcasts on DVD sales and internet piracy. MIS Q 33(2):321-338

42. Smith MD, Telang R (2010) Piracy or promotion? The impact of broadband Internet penetration on DVD sales. Inform Econ Policy 22(4):289-298

43. Stenbacka R, Tombak M (1994) Strategic timing of adoption of new technologies under uncertainty. Int $J$ Ind Organ 12(3):387-411

44. Teece D (1986) Profiting from technological innovation: implications for integration, collaboration, licensing and public policy. Res Policy 15(6):285-305

45. Tsay AA, Agrawal N (2004) Channel conflict and coordination in the e-commerce age. Prod Oper Manag 13(1):93-110
46. Waldfogel J (2009) Lost on the web: does web distribution stimulate or depress television viewing? Inform Econ Policy 21(2):158-168

47. Yan R, Pei Z (2009) Retail services and firm profit in a dualchannel market. J Retailing Consum Serv 16(4):306-314

48. Yao DQ, Liu JJ (2005) Competitive pricing of mixed retail and e-tail distribution channels. Omega 33(3):235-247

49. Yoo WS, Lee E (2011) Internet channel entry: a strategic analysis of mixed channel structures. Market Sci 30(1):29-41

50. Yue X, Liu J (2006) Demand forecast sharing in a dual-channel supply chain. Eur J Oper Res 174(1):646-667

51. Zhu K, Weyant J (2003) Strategic decisions of new technology adoption under asymmetric information: a game-theoretic model. Decis Sci 34(4):643-675 